\title{
Espanhóis na Santos da bèlle époque: $O$ espaço expressão da contradição. Resultados preliminares de uma pesquisa
}

\author{
Marília Dalva Klaumann Cánovas \\ CEDHAL - Universidade de São Paulo
}

Há algumas décadas definimos nosso objeto de estudo em torno do imigrante espanhol que, na imigração em massa - basicamente ocorrida entre os finais do século XIX e as primeiras décadas do século XX deixou várias regiōes de seu país, escolhendo o Brasil como seu país de destino e, neste, fixando-se no Estado de São Paulo.

Com essa perspectiva, dentro da proposta de dar visibilidade ao importante contingente imigratório espanhol, cujo volume aponta para cifras que o posicionam entre os três principais contingentes europeus a demandarem o Brasil até os finais da década de 1920, realizamos duas grandes investigações. $\mathrm{Na}$ primeira delas, que resultou em nossa Dissertação de Mestrado, posteriormente publicada, ${ }^{1}$ buscamos recuperar sua trajetória no núcleo cafeeiro do Oeste Paulista, para onde espanhóis eram enviados, em conformidade com um bem articulado programa oficial de captação de braços na Europa, destinado a irrigar, com mão-de-obra farta e, portanto, barata, as lavouras de café.

Durante a realização dessa investigação, em que pese a dificuldade na localização das fontes, além de sua fragmentação e escassez, questôes já fartamente sinalizadas por outros estudiosos - o que, de certo modo, poderia ser responsável pela exígua produção preexistente sobre a temática - foram sintomáticos indícios e referências que sinalizavam para um outro espaço, insinuando a presença espanhola para além das fronteiras dos cafezais, apontando para as cidades, destacadamente para São Paulo e Santos, em virtude da importância assumida por ambas na economia do café.

Em decorrência disso, como desdobramento do trabalho anterior e devido à inegável magnitude alcançada, definimos como foco de nossa 
investigação para o doutorado - trabalho também publicado ${ }^{2}$ - o fenômeno migratório espanhol na cidade de São Paulo, na Paulicéia nascente que, passando por uma metamorfose radical na passagem para o século XX, se transformaria, de maneira acelerada, de pequeno núcleo urbano na Metrópole do café.

Para ali, o espanhol, cujo percentual de direcionamento para o Estado de São Paulo revelou uma segunda posição no quadro geral das imigrações do período, era atraído pelo seu desenvolvimento, pelas oportunidades que então despontavam e pela perspectiva de trabalho.

Atualmente, em complemento à pesquisa anterior, vimos realizando um pós-doutorado focalizando a cidade portuária de Santos (SP) que, por sua especificidade no conjunto das transformaçōes decorrentes da economia do café, passou a apresentar um crescimento vertiginoso e um acelerado processo de urbanização, resultante da expansão das atividades comerciais e de serviços, cujos indicadores se evidenciaram no decurso das pesquisas anteriores.

Santos era tão somente um pequeno povoado de pouco mais de nove mil habitantes, segundo o Recenseamento de 1872. Ali vivia uma maioria de brancos (55,3\%), entre mestiços, negros e índios, dos quais 17,2\% eram estrangeiros.

No entanto, foi no contexto das décadas finais do dezenove que a cidade apresentou um significativo salto de crescimento, decorrente do incremento da atividade exportadora, graças à inauguração da Estrada de Ferro Santos-Jundiaí, em 1867, que abriu a possibilidade de escoamento da crescente produção cafeeira do interior do Estado.

Os negócios movidos a aroma de café revolucionariam a cidade: eram empresas comissárias e exportadoras, firmas corretoras, armazéns gerais e bancos que vinham coroar a sua radical metamorfose, alterando radicalmente a sua função. Até então, os negócios com o café davam-se entre o fazendeiro e uma casa comercial, a quem aquele consignava a sua produção. Intermediárias entre o produtor e as exportadoras, cabia-lhes o percentual de $3 \%$ pelo volume negociado com estas que embarcavam o produto para as firmas importadoras.

O termo casas comissárias teria sido cunhado somente a partir da década de 1890 quando a cidade exibia trinta delas. Com o passar do tempo, as casas comissárias começaram a funcionar como bancos do produtor, estocando o produto e regulamentando a oferta. Nessa esteira, a construção 
do porto moderno, cujo primeiro trecho foi inaugurado em 1892, veio reafirmar a importância que gradualmente a cidade vinha assumindo.

Até então, as condiçôes físicas, higiênicas e técnicas do porto eram deploráveis. As mercadorias importadas ou aquelas que aguardavam o embarque eram amontoadas às margens do estuário, permanecendo em pequenos pátios improvisados de terra e expostas ao relento. Essa condição provocava a prática da rapinagem, de modo que era impossível às autoridades garantir a mercadoria desembarcada aos seus donos. Do mesmo modo, até 1886, dificilmente um navio, que já aguardara meses para descarregar, atracava nas pontes sem encalhar, tamanho o lodaçal que obstruía o canal. Consta que o terreno onde se executaram as fundações da muralha do cais tinha grande profundidade de lodo.

Da mesma forma que no porto, as condições sanitárias da cidade eram lastimáveis. Sua população era vitimada pela febre amarela, que atacava a sua população desde 1850; pela varíola; pelo impaludismo e até mesmo pela febre bubônica. Até o último quartel do dezenove a cidade possuía apenas seis chafarizes públicos, não possuindo água encanada e nem esgotos. As matérias fecais eram despejadas nas praias ou nos córregos. $\mathrm{O}$ despejo, como era chamado, era levado pelos escravos domésticos em grandes vasos de madeira, ocasião em que as janelas eram trancadas, tamanho o odor que exalava nas casas próximas à praia. Essas praias lodosas e sujas também eram o depósito de todo o lixo da cidade que ali aguardava as marés mais altas, para sua dispersão, o mesmo ocorrendo com os gabinetes sanitários, que não passavam de estacas fincadas sobre o mar. Quando realizado nos córregos, o acúmulo do despejo redundava em lodaçais fétidos. ${ }^{3}$

Pólo receptor de mão-de-obra destinada ao núcleo cafeeiro, Santos viu sua população quase decuplicar em trinta anos, pelo impacto da imigração. Assim, pelo recenseamento levado a efeito na cidade em $1913,{ }^{4}$ vimos crescer enormemente o número de habitantes, ao mesmo tempo em que se alterava radicalmente a composição de sua população. Santos alcançava, então, o número de 88.967 habitantes, com um percentual de 42,5\% de estrangeiros, dentre os quais a maioria era de origem portuguesa. $\mathrm{O}$ espanhol representava o segundo grupo imigrante em expressão, com pouco menos de $10 \%$ do total de sua população.

Essas premissas centrais orientam algumas de nossas hipóteses, cuja análise vimos procedendo e buscando refletir, nesse momento, com base em relevante corpus documental, abaixo referido. 
Em primeiro lugar, parece razoável refletir sobre a atmosfera tumultuada e o cenário conflituoso por excelência que passou a exibir a cidade, em decorrência das crescentes levas de imigrantes, de diferentes etnias, que ali se fixavam. Sabe-se que, em 1920, a cidade de Santos acomodava um universo multiétnico: ao convívio dos nativos, além de portugueses e espanhóis, o contingente majoritário, também se juntavam italianos, turcos e japoneses e outras quinze nacionalidades minoritárias.

Esse dado, por si só, não se traduziria em problema se ao inchaço populacional da cidade correspondessem condiçôes mínimas para a sua absorção. De fato, a Santos cosmopolita passou a apresentar expressivos sinais de modernização, especialmente conduzidos por Saturnino de Brito, prefeito e engenheiro sanitarista, por cujas mãos a cidade passou a receber uma série de melhoramentos urbanos, como rede de canais, abertura de novas avenidas e uma linha de bonde de burro.

Ao mesmo tempo, era grande o empenho do poder público no estabelecimento de uma política sanitária no Estado de São Paulo, na reorganização e vigilância do espaço, disciplinando higienicamente a moradia, o bairro e toda a cidade, agindo preventivamente como forma de controle social contra o vírus da desordem. Tudo indica que o impacto da chegada dos imigrantes teria desequilibrado as condições de salubridade da cidade, com a eclosão de diversas outras doenças, por eles trazidas. Como recíproca, a massa estrangeira recém-chegada também teve que enfrentar as doenças tropicais, exóticas ao seu organismo, provocando, como resultado, um choque entre populações imunologicamente distintas. ${ }^{5}$ Assim, instituiu-se Comissão Sanitária Estadual, que respondia pelo controle das epidemias, pelas desinfecções, pelos cortiços e pelas lavanderias públicas, enfim, por todos os possíveis focos de doenças infectocontagiosas. A propósito, a epidemia de febre amarela, que muito antes desembarcara naquela cidade, no ano de 1889 , adquiriria proporções alarmantes em seu ritmo acelerado de propagação que, acompanhada de varíola, atingiria $10 \%$ de toda a população. ${ }^{6}$

Apontava-se como responsável pela epidemia o grande número de cortiços insalubres, praticamente inabitáveis, verdadeiros cubículos fabricados de tábuas de caixote e cobertos de folhas de zinco, onde viviam famílias numerosas. Eles eram alugados por senhorios que se opunham à sua demolição, pretendida pela Comissão Sanitária. Além delas, havia também as cocheiras-cortiços, habitações construídas em palanques sobre as baias, onde viviam os cocheiros, muitas vezes com a família. Ambas as 
habitações coletivas não tinham água nem esgotos e, segundo Álvaro Guilherme, cronista e médico sanitarista do Hospital de Isolamento que acabaria por ser inaugurado na cidade, elas serviam "para albergar a numerosa imigração chegada em busca de trabalho remunerador e certo".7

A considerar a análise de Munhós quanto à nacionalidade do atingido pela febre amarela, estudo que abrangeu doze anos (1876 a 1887), constatamos que a maioria delas tinha origem européia $(78,7 \%)$ e apenas $17 \%$ eram de brasileiros, dos quais apenas $2,2 \%$ pertencia a pessoas de cor - negros, pardos, crioulos, conforme indicação das certidões de óbitos analisadas pelo autor, que conclui pela menor suscetibilidade à doença dessas populações. ${ }^{8}$

O recenseamento de 1890, apesar do grande afluxo migratório, apontaria decréscimo populacional, tanto pelas mortes provocadas pela grande epidemia quanto pela evasão da população, sobretudo a da camada mais abastada.

Esses imigrantes, desembarcados em grande aglomeração, haviam cruzado o oceano em condições desumanas de higiene e asseio e, infectados, eram considerados focos ambulantes de doença. Nos finais da década de 1880, quando não podiam embarcar para São Paulo no mesmo dia - como era o desejo dos governantes -, eles ficavam em um casarão na Ilha do Barnabé, antes utilizada como cocheira, local absolutamente impróprio, tanto quanto o que o sucedeu, junto ao Monte Serrat até, finalmente, ser construído o Edifício da Imigração.

A cidade, portanto, apesar dos sinais eloqüentes de progresso, apresentava, simultaneamente, um outro lado, o do avesso, em que eram muitos os paradoxos.

Nosso objetivo nesse artigo, a partir dessas premissas centrais, resumese a dialogar com a documentação de apoio e do ponto de vista do imigrante espanhol, objeto de nossa investigação, de que modo a demonstrar como a cidade - frente ao ritmo acelerado imposto pelo repentino e vertiginoso crescimento - acomodava as crescentes levas de imigrantes que ali se estabeleciam e, do mesmo modo, como eles reagiam frente às tensões urbanas geradas por esse quadro.

Para tanto, buscaremos refletir sobre a dinâmica que passou a se operar entre os diferentes grupos constituídos, nacionais e estrangeiros, o modo e a intensidade como estes se articulavam, apropriando-se do espaço e fazendo a mediação entre os seus valores e padrões culturais, e o modus operandi que singularizou a corrente espanhola 
Não parece escuso partir de um pressuposto que aponta para um cenário de conflitos, irremediável diante da explosiva combinação de seus atores. Assim, não se pode negligenciar alguns fatores, diretamente relacionados ao perfil dos habitantes da cidade, onde se misturavam uma população heterogênea composta por nacionais e ex-escravos, aos quais se mesclavam os estrangeiros, oriundos de diferentes países, com culturas e expectativas distintas. Outro importante aspecto a ser considerado é que, com essa massa flutuante que por ela circulava, em um movimento ininterrupto e imprimindo-lhe um caráter de transitoriedade, também desembarcavam as idéias libertárias que vinham agitando o cenário europeu.

Esse incessante vai-e-vem de estrangeiros que circulava pela cidade, refletindo uma contínua mobilidade, constituiu uma das marcas do período. Não era, contudo, apenas internamente que se processava esse processo indissociável ao imigrante do período; ele também abrangia os três países do cone sul americano, especialmente a Argentina. A contínua itinerância que se observou no período em diversas direções, refletia, por outro lado, o grau de instabilidade e o modo precário de acomodação que marcou a trajetória de boa parcela desses indivíduos.

Os relatórios oficiais vinham apontando para o fato de as saídas de emigrantes superarem as entradas, no movimento global, denunciando o fato de que muitos emigrantes, embarcados com passagem subvencionada até Santos, uma vez na cidade, dali prosseguiam viagem por conta própria para os países platinos, especialmente para a Argentina, ao mesmo tempo em que era registrado o aumento no número de repatriamentos, a partir de 1887 .

A Argentina sempre significou a pedra no sapato de nossa política imigratória e era fato corriqueiro a preferência dos imigrantes por aquele país, ao qual se atribuíam distintas justificativas: "[Na Argentina] no ocurre como en el Brasil, donde, a mas de ofrecer graves inconvenientes para la salud, los naturales tienen odio letal a los extraños", afirmaria uma autoridade diplomática espanhola, em 1911.

Essa mobilidade do imigrante deveria receber uma maior atenção por parte da historiografia, porque ela é reveladora do grau de instabilidade e da inquietação que a geravam, ao qual podem ser creditados outros indicadores especialmente relativos à questão social.

Historicamente, o ano de 1898 é considerado o marco inicial desse fenômeno que, então, teria sido provocado pela queda nos preços do 
café, resultante da superprodução, que implicou em substancial baixa nos salários dos trabalhadores agrícolas.

Como é de se prever, isso também ocasionou quebra ou descumprimento de contratos, situação inevitavelmente aliada à marcha itinerante e ao êxodo contínuo de colonos estrangeiros que passaram a deixar as fazendas em direção às cidades, em busca de trabalho e condições de sobrevivência. ${ }^{10}$

Nem todos os colonos que abandonaram a sua fazenda após a colheita se engajaram nas fazendas vizinhas; cada ano, a colheita assinala um novo movimento de concentração da população rural para os centros urbanos. Esse movimento é ininterrupto /.../. Todas as cidades do Estado, inclusive a capital, são povoadas por velhos imigrados que romperam com o trabalho agrícola. ${ }^{11}$

Outros fatores, porém, também devem ser conjugados às crises conjunturais da economia cafeeira, dificultando a permanência dos colonos no interior, dentre as quais as epidemias de febre amarela que, na última década dos Novecentos, atingiram especialmente as imensas regióes do Oeste Paulista. ${ }^{12}$

Meus bisavós estiveram na Fazenda Monte Alto, por volta de 1893/ 5. Comeram o pão que o diabo amassou ali. A mãe da minha 'bisa' perdeu dois filhos de febre amarela e foi banida para o mato com eles queimando de febre. Os dois morreram e ela os enterrou cavando as suas sepulturas com as próprias mãos. Fugiram dali a pé até a cidade de Santos, onde se estabeleceram e meu 'bisa', Enrique Alvarez Corisco, fundou a Sociedad Española de Repatriación. ${ }^{13}$

De acordo com esse depoimento, a criação de associaçôes de ajuda mútua ou, como o caso, de repatriação, era fruto de amargas e dolorosas experiências pessoais revertidas em iniciativas que visavam a amparar e amenizar desafortunados em igual situação.

Outra questão eram os constantes conflitos dos imigrantes com fazendeiros, administradores das fazendas ou os capangas das mesmas. Esta talvez tenha sido a razão da fundação, em 1903, da Liga Española de Defensa Mutua, criada com o fim precípuo de oferecer assistência jurídica a seus associados, instalada com subseçôes funcionando em cidades do interior para atender a demanda de reclamaçôes dos imigrantes contra os fazendeiros.

Durante todo o período analisado (1912/22), foram constantes as manifestaçôes de repúdio, expressas em matérias publicadas no periódico 
El Diario Español (EDE) por seu criador, José Eiras Garcia, face à realidade dos colonos, às contendas entre estes e os fazendeiros e à miserável condição de vida da maioria dos imigrantes na cidade, muitos dos quais, como ele próprio, perseguidos pela polícia.

Era patente que o jornal de Eiras Garcia de há muito incomodava os interesses dos fazendeiros, a quem desafiava, denunciando ou procurandoos pessoalmente para negociar os contratos dos imigrantes que se sentissem lesados. Por essa razão, passou a sofrer ameaças, tendo sido processado por um fazendeiro, e preso, em 1907, quando solicitava ajuda aos paisanos para as custas dos processos que então moviam contra fazendeiros.

A esse propósito, pudemos constatar intensa movimentação da colônia do interior e da capital do Estado de São Paulo e da cidade de Santos, especialmente por parte do Centro Galego da Capital em seu favor. Provavelmente motivada por sua prisão, foi proposta e aceita pela diretoria da Sociedade Espanhola de Socorros Mútuos da capital uma "ampliação do Regulamento" pela qual caberia à mesma a "defesa dos associados em caso de manifesta perseguição ilegal por parte de qualquer poder ou entidade" (Assembléia de 26.09.1908).

Nos inícios da década de 1920, provavelmente em função do crescente volume de espanhóis já instalado no núcleo cafeeiro e do acirramento das relaçôes entre fazendeiros e colonos, torna-se nítida uma abordagem mais agressiva por parte do EDE (leia-se Eiras Garcia), que passou a encaminhar as questôes de violência contra os paisanos por parte dos fazendeiros que lhe eram relatadas. O discurso agora vigente, e que ganhava as primeiras páginas, denunciava: "es sabido que aqui las garantias son letra muerta cuando las invoca el humilde, el flaco, el explotado (...) contra la brutalidad de hacendados", ${ }^{14}$ e acusava a falta de respeito dos fazendeiros, que não cumpriam os contratos e que maltratavam os colonos, condenando-os à miséria. A esse discurso seguia-se, quase sempre, a íntegra de uma carta enviada à redação por um colono, relatando infortúnios e passagens degradantes geralmente ocorridas nas contendas com os administradores das fazendas.

Todos esses fatores, aos quais ainda se associavam outros, como a falta de perspectiva e a inadaptabilidade às condições locais adversas, além do impacto provocado pelas precárias condições de vida e trabalho na lavoura e a baixa remuneração decorrente de contratos quase inteiramente comprometidos com as suas despesas de subsistência, levavam esse imigrante a peregrinar com sua família de fazenda em fazenda, em uma 
constante itinerância, em busca de condiçôes mais favoráveis que garantissem a possibilidade da acumulação de algum pecúlio, que se destinava prioritariamente ao retorno a seu país de origem - sonho acalentado, porém de difícil concretização -, ou à aquisição de alguma (pequena) propriedade.

De conformidade com as estatísticas oficiais, no período da grande emigração em massa, de cada 10 imigrantes desembarcados no Porto de Santos, oito deles destinavam-se às zonas cafeeiras. ${ }^{15}$

Especula-se que, do restante, parte tenha permanecido na própria cidade de Santos, burlando a fiscalização de desembarque. Os demais, embarcados para a cidade de São Paulo, eram instalados na Hospedaria dos Imigrantes, por força de contratos previamente pactuados, pelos quais, na categoria de imigrante, fazia-se a concessão da passagem pelo governo estadual.

Nesse particular, Santos apresentava-se como um diferencial favorável frente às demais localidades do ponto de vista do imigrante que, fugindo ou não do colonato, buscava uma tábua de salvação nas cidades: todos por ela já haviam transitado e, se levarmos em conta a sua geografia, é provável que muitos espanhóis procedentes de cidades banhadas pelo oceano, preferissem nela se fixar.

\section{As associaçôes étnicas de ajuda mútua de Santos}

Consta ter sido a cidade de Santos a primeira do Estado a exibir uma agremiação étnica - a Sociedade Centro Espanhol criada em 1895 - em cuja esteira se seguiram outras, tanto na Capital, ${ }^{16}$ como em cidades do interior tributárias do café e fortemente marcadas pela presença de imigrantes contratados pelas fazendas. ${ }^{17}$

O Centro Espanhol teve importante função junto aos recém-chegados ou aos refluídos do campo, no sentido de orientação, assistência, amparo em caso de doença e acolhimento em um primeiro momento e depois, auxiliando-os a encontrarem alguma ocupação, fatores que propiciavam um mínimo ajustamento ao imigrante que o procurava, mergulhado em extrema pobreza e muitas vezes apresentando desajuste psíquico.

Sua criação, prematura se levarmos em conta o ainda reduzido número de espanhóis ali radicados, revela o abandono a que os imigrantes eram submetidos pelo seu próprio país de origem, aqui representado pela autoridade consular e o corpo diplomático. Denunciando também, por outro lado, o desamparo a que estavam sujeitos pelo poder público do 
país de destino, para quem o (indesejado) imigrante que passava a habitar os centros urbanos representava, de certo modo, o elemento que, burlando as determinações, punha em relevo a falha do eficiente aparato oficial montado para a captação de braços para a lavoura cafeeira.

Era justamente no vazio do poder público que se colocavam essas associações, muitas delas extrapolando o caráter meramente assistencial, embora a manutenção da saúde representasse o elemento essencial para que o sujeito se mantivesse ativo no processo produtivo, condição para a sua sobrevivência.

O Centro Espanhol de Santos originou-se da iniciativa de um imigrante bem posicionado socialmente na cidade, José V. Bojart Por sua iniciativa, foi publicado no diário da cidade, em $1^{\circ}$ de janeiro de 1895 , uma convocatória para uma reunião que se daria na Rua Marques de Herval, 78, à qual acederam diversos conterrâneos, dentre os quais José Pascual Gómez, proprietário da Pascual \& Gómez \& Cia., agência de passagens na cidade de São Paulo, com filial em Santos, e anunciante no EDE desde 1913. ${ }^{18}$ Dias mais tarde, em nova reunião, elegeu-se uma direção provisória, cujo presidente interino foi Manuel Troncoso.

A esta sociedade, deu-se, inicialmente, o nome de Casino Español. Em março do mesmo ano a instituição adquiria um terreno na Rua Aguiar de Andrade, no Paquetá, no valor de sete contos de réis, e no mês de maio era lançada a pedra fundamental para o início das obras da sede, para cuja construção lançaram-se 205 ações à venda. Ao projeto original acresceu-se a construção de um teatro e uma escola.

Foi um período de dificuldades enfrentado pela sociedade, no qual se buscava conciliar a receita destinada para as obras com as despesas da prestação de assistência aos sócios afiliados, especialmente com despesas hospitalares ou fúnebres. As questōes envolvendo os fundos para a sua manutenção receberiam, durante todo o período analisado, atenção redobrada por parte de sua direção. As doações em dinheiro feitas por membros da colônia faziam-se necessárias e eram mencionadas nas Atas com os nomes dos doadores, pessoas físicas ou jurídicas, e as respectivas quantias doadas.

Seus salóes e o palco cênico passaram a ser requisitados, a título de empréstimo, para diversas comemoraçóes, reuniōes, eventos beneficentes, bailes, concertos, etc. Também servia de abrigo a sobreviventes, como o ocorrido com o vapor Príncipe de Astúrias, em 1916. ${ }^{19}$ 
A instituição também cedia seus espaços a outra agremiação da colônia, a Sociedade de Repatrição, fundada em 1902 que, sempre às voltas com questões financeiras, não havia ainda podido, anos depois, ter a sua própria sede. Seus sócios, cuja contribuição mensal era de 2 mil réis, podiam requerer a repatriação, motivada por doença ou viuvez da mulher com filhos pequenos, após dois anos de contribuição, regra que era flexibilizada em casos especiais de enfermidade que impossibilitassem o exercício do trabalho. A média de repatriações, até a guerra civil, foi de 35 a 40 pessoas por ano. ${ }^{20}$

Em 1919, essa Sociedade contava com 716 sócios e havia repatriado, no exercício 1917/18, a quinze deles e a nove indigentes, também espanhóis. $^{21}$

Essas dificuldades devem ter pesado na decisão da aglutinação dessas duas sociedades que, enfim, visavam a um mesmo objetivo e, basicamente, complementavam-se. À junção das duas agremiações sucedeu-se a alteração da sua razão social, que passou a se denominar Centro Espanhol e Repatriação de Santos.

De fato, a repatriação representava a única alternativa para muitos imigrantes: velhice, viuvez ou o abandono do marido, no caso das mulheres, e enfermidades diversas, como a tuberculose e a paralisia, além dos distúrbios psíquicos, eram as razões mais comumente mencionadas para a autoridade consular, a quem recorriam com o pedido da passagem para o retorno, que se dava, no mais das vezes, em condições ainda mais deploráveis do que as que haviam motivado a vinda. $\mathrm{O}$ infortúnio atingia também a muitos menores, órfãos de pais e que, nessa condição de abandonados, eram recolhidos a algum albergue até que se desse o destino de devolvê-los a seu país de origem.

\section{O Consulado Espanhol de Santos (CES) e as fontes para a pesquisa}

O Consulado General de España da cidade de São Paulo foi criado em 1893, em uma clara evidência do gradual aumento do contingente imigratório espanhol naquela cidade. Informações extra-oficiais não comprováveis indicam que, antes dele, já existia o Consulado de Santos. A considerar a data inicial dos registros ou a inscrição dos residentes daquele distrito consular, porém, a data oficial de abertura do Consulado de Santos é 1898, ano em que se iniciou o inventário dos súditos espanhóis ali residentes.

Para efeito dessa nossa pesquisa, a série com que vimos trabalhando compreende os anos de 1898 até 1922 (25 anos), abrangendo aproximadamente 
doze mil registros nominais, ${ }^{22}$ praticamente uma radiografia da trajetória de vida de cada indivíduo ali inscrito, constituindo importante indicador e ensejo para a exploração de uma multiplicidade de aspectos.

Dependendo do escrevente, compilava-se um número maior ou menor de informaçôes sobre o declarante, ocasionando falhas e lacunas nos registros, em determinados períodos. Ainda assim, de modo geral, e esse foi um dos critérios para sua eleição, esse conjunto de livros, que tem suas séries bem conservadas, apresentou, com regularidade variável, um somatório de informações importantes sobre o imigrante, cujos dados, transcritos manualmente e depois informatizados em planilha eletrônica, podem ser cruzados e operacionalizados, gerando uma série de relatórios.

Tal registro, em tese, constituía prática legal obrigatória a todos os imigrantes, ainda que não houvesse como os obrigar a realizá-lo, de modo que é imperioso lembrar da parcela daqueles que, por desconhecimento, desinteresse, puro descaso com a autoridade consular ou especialmente falta de recursos, não o realizaram. Informes extra-oficiais de atuais funcionários do Consulado dão conta de que era obrigatório o recadastramento a cada dois anos, e de que, nessa ocasião, era expedida uma cédula, da qual se originava a Carteira de Estrangeiro.

No início do período analisado, a maioria dos registros pertencia exclusivamente a elementos do sexo masculino, prática que gradualmente foi sendo estendida também às mulheres, porém sempre em menor escala.

\section{O periódico étnico como outra fonte de pesquisa}

Quase simultaneamente à criação do CES deu-se o aparecimento de um periódico em língua espanhola na cidade de São Paulo, o El Diario Español (EDE), iniciado também em 1898, e cuja série, localizada para exame, com pequenas lacunas, engloba os anos de 1912 a 1922, datalimite de sua circulação e que coincide com os anos finais examinados nos livros consulares.

A primeira edição da série que examinamos, no $15^{\circ}$ ano de sua publicação, foi a de número 984 . Seu exemplar custava então 100 réis. A sua composição gráfica, bastante variada, não seguia um padrão rígido. Durante todo o período avaliado, via de regra circulou com quatro páginas (ocasionalmente com seis e raramente com oito) e seis colunas. Nestas, notamos certa divisão temática por matérias, nada rígida, que, de certo modo, respeitava uma hierarquia aplicada diferentemente a cada período 
analisado, atribuindo ou não posição de destaque a determinados assuntos, em dado momento.

De modo geral, no entanto, os textos, anúncios, reclames, matérias e seçôes ali contidos testemunham o quadro histórico em que foram produzidos; em outras palavras, fica clara a sua produção historicamente determinada, enquanto registro comprometido com um dado contexto específico.

Evidencia-se, por exemplo, a estreita relação que havia entre as colonias espanholas das duas cidades, São Paulo e Santos, fato revelado pelo conjunto de matérias publicadas diretamente relacionadas a elas, visando atender os interesses do seu público-alvo, estampando ocorrências civis, como as efemérides sociais, por exemplo.

Especialmente referidos a Santos, pode-se constatar inúmeros reclames contemplando seus estabelecimentos comerciais de diferentes segmentos, incluindo os hoteleiros, pertencentes à colônia na cidade, como também a série de matérias envolvendo a programação sócio-esportiva da cidade; as convocações para ingresso nas sociedades e agremiações da colônia; as notas sobre eleições de seus dirigentes; as convocações para as festas que se promoviam, etc.

No quesito reclame, as páginas do EDE acolhiam anúncios periódicos das empresas de navegação com informes sobre as saídas e os destinos dos navios e dos vapores de viagem. Também se tornaram comuns os anúncios publicitários ligados às Casas Importadoras, especialmente de gêneros alimentícios e bebidas, com destaque para o vinho produzido na Espanha, evidenciando a existência de um mercado consumidor mais refinado e/ou com maior poder aquisitivo. Entrementes, já aqui se delineava o grande balcão de mão-de-obra representativo dessa cidade em construção: solicitase e se oferta, em qualquer espaço do jornal, mão-de-obra para diferentes colocações e empregos, durante todo o período até então analisado.

Outra seção bastante concorrida é a de personas buscadas. Nela, publicavase o nome, a origem, a data de chegada e o suposto último domicílio do indivíduo procurado, em um claro indicativo de como as famílias se desintegravam e perdiam o contato com seus membros, também emigrados.

As fontes literárias

No mais, ainda temos nos municiado de outras possibilidades, não menos interessantes e ricas em termos de abordagem, algumas das quais 
reveladas pelas narrativas literárias e memorialísticas sobre a cidade de Santos. Conduzidas quase sempre pela preocupação em registrar as múltiplas transformações que se iam impondo àquela, até então, inexpressiva cidade - falando da gente que nela habitava e de seus costumes, particularizando singularidades das colônias de estrangeiros que nela se fixavam, demarcando sua fisionomia e as múltiplas tensões que experimentava -, tais registros deixam-nos informes de reconhecido potencial histórico. ${ }^{23}$

Desse modo, e cada qual com a sua especificidade e seu potencial, essas fontes principais se complementarão, em uma conjunção com outras eventuais e com a bibliografia específica, em uma operação em que buscamos desvendar aspectos que, em seu conjunto, possam atribuir uma feição ao espanhol que viveu na cidade de Santos, dotando-lhe de maior visibilidade.

\section{As primeiras imagens do espanhol na Santos da bélle époque}

Remontam à segunda metade do dezenove as primeiras menções documentais a espanhóis estabelecidos com comércio na cidade de Santos. Com efeito, no Arquivo Nacional (RJ) localizamos, na série Indústria e Comércio o registro de matrícula de estabelecimentos comerciais pertencentes a eles naquela cidade.

Os primeiros registros remontam ao ano de 1852 e admitiam a matrícula dos estabelecimentos pertencentes a José Manoel Alfaia Rodrigues, com comércio de "consignações" de varejo e atacado de "molhados e louça" e o estabelecimento de Felipe Santiago Colmenero, com comércio de "gêneros nacionais por atacado". ${ }^{24}$

Do mesmo modo que os anteriores, também Manoel Candido Silvarinho tinha seu estabelecimento de "molhados por atacado e a retalho", cuja matricula foi admitida em 1865. ${ }^{25}$ Já João Candido Silvarinho, provavelmente aparentado do anterior, apareceu em 1883, com comércio de molhados e comissóes. ${ }^{26}$

No tocante ao período em pauta, que guarda especificidades históricas relacionadas à emigração ultramarina em massa, contudo, cabe ressaltar que o adensamento então verificado contém algumas singularidades.

Em primeiro lugar, um dado revelador e instigante quanto à origem local desse contingente: ele era majoritariamente oriundo de uma única região da Espanha: a Galícia, com percentuais que atingiram, no primeiro decênio analisado (1898-1907), a aproximadamente 78\%. 
Consideradas as quatro províncias galegas, Orense desponta como a que mais se fez representar, apresentando sozinha, no total de galegos fixados na cidade no período, o percentual de 52,2\% (Riós e Refogos como as localidades de maior incidência).

A Província de Pontevedra, colocada em segundo lugar, surge com um índice de 41,1\% (Goyan e Cresciente como origens principais), enquanto La Coruña surge com 5,5\% e Lugo com apenas 1,2\%.

Quanto às datas de chegada desse imigrante, o ano de 1866 apresentouse como a data de ingresso mais antiga; nos demais anos, a oscilação pode ser considerada pequena, excetuando-se os anos de 1905 e 1906, sobretudo este último, quando o contingente registrado praticamente dobrou.

Quanto ao gênero, há evidência de que os espanhóis integravam um perfil basicamente masculino, diferente do conjunto familiar que, no mesmo período, mas provavelmente oriundo de outras províncias espanholas, dirigia-se ou refluía do colonato.

Em outra variável também a corrente instalada na cidade de Santos, nesse decênio, era diferente: tratava-se dos indivíduos alfabetizados. Com efeito e surpreendentemente, $80 \%$ dos declarantes diziam saber ler e escrever, dado este que remete, como cotejamento, aos contingentes majoritários da Andaluzia que se fixaram no colonato e na cidade de São Paulo, que apresentavam altos índices de analfabetismo.

Assim, dos inscritos domiciliados na cidade de Santos no período abrangido pela primeira década da pesquisa (1898/1907), quanto a gênero e estado civil, verificamos que, no primeiro decênio $96,7 \%$ dos registros pertenciam a elementos do sexo masculino $-52 \%$ dos quais solteiros, revelando-se, aqui também um perfil completamente diferente dos localizados para a cidade de São Paulo, em sua maioria casados.

Nesse caso, os indicadores nominais dos registros consulares sugerem vários elementos do sexo masculino pertencentes a uma mesma família (irmãos; primos; tios, etc.), insinuando a provável existência de redes microssociais ou cadeias migratórias, que representavam apoio adicional na decisão da saída, por fornecerem referências concretas aos interessados.

A esse indicador, que aponta para uma maioria de homens solteiros, pode-se acrescer um outro, referido à faixa etária. Com efeito, tratava-se de homens em uma faixa etária média de 25 anos, com a idade mínima de 15 e a máxima de 63 anos. 


\section{Dôssie Imigração}

Outro dado refere-se à categoria laboral desse contingente, ou seja, à profissão declarada nos registros consulares. Desse modo, considerado o conjunto dos registros, há três categorias que se sobressaem às demais, a saber: a de jornalero, a de operário e a de comércio, sendo que a primeira categoria, a de jornalero, alcança o elevado índice de $42 \%$ no conjunto, considerada a década aqui examinada (1898/1907). Justificadamente, acreditamos.

À cidade em construção aportavam milhares de homens sem qualificação profissional, trabalhadores pobres, em geral oriundos do campo espanhol e especialmente da região galega, gerando um excedente de mão-de-obra que se alimentava de tarefas ocasionais e improvisadas e de modo descontínuo. Eram provenientes especialmente de Orense, aparecendo Pontevedra numa segunda colocação, ao que corresponde o perfil de origem dessa coletividade.

Como era previsível, muitos dessas ocupações vinculavam-se a atividades e funçôes marginais ao processo produtivo da nova conjuntura urbana que, por suas características, apresentam de difícil aferição documental. Trata-se de uma vasta rede de atividades à margem dos registros oficiais, que, por sua própria natureza e características, se vinculariam a atividades e ocupaçôes eventuais e de pouco ganho, a pequenas tarefas ocasionais, ao subemprego e a serviços autônomos, enfim, a inumeráveis atividades incluídas na chamada economia invisivel, ou oculta, informal, paralela, improvisada, etc.

A essa categoria volátil agregavam-se todos aqueles que, de uma forma ou de outra, inseriam-se em seus espaços econômicos de forma nãoregular, no exercício de atividades exploradas de forma diferenciadas, através das brechas de ocupaçôes e ofícios que se abriam ao sabor das demandas apresentadas. Essa improvisação encontrava passe livre frente ao trabalhador nacional, marcado pelo forte preconceito herdado da sociedade escravista quanto ao trabalho manual.

Interessante observar os locais de moradia da maioria desses sujeitos, cuja concentração sugere ruas e bairros populares com precárias condições sanitárias. Na Vila Macuco, em geral, predominavam os trabalhadores do cais, como também na área do antigo quilombo do Jabaquara. Também os vimos, nessa década, residindo na Rua do Rosário, provavelmente no cortiço ali existente, ${ }^{27}$ ou na Vila Matias, núcleo de um novo arrabalde, ${ }^{28}$ onde a malária grassava. As habitações coletivas eram também grandes focos de febre amarela, porém, como vimos, era grande a resistência dos senhorios para a sua demolição. 
Foi nesse cenário, em uma época em que a cidade, geralmente possuindo um clima quente, não tinha água encanada, que o negócio de José Caballero, galego de Pontevedra, tinha tudo para prosperar. Com efeito, em 1876, aproveitando-se, com senso de oportunidade, de uma brecha oferecida, ele se estabeleceu com uma casa de banhos na cidade. Não era pioneiro no negócio; seu estabelecimento seria o segundo do gênero até então.

Em seus anúncios, oferecia banhos frios e quentes, e a possibilidade de uma assinatura mensal, válida para trinta banhos. Em sua casa de banhos, que funcionava em um trecho da atual Rua XV de novembro, antes conhecido como Rua Antonina, também funcionava uma espécie de bar, onde se serviam bebidas e cervejas geladas.

Observe-se, porém, que Caballero havia aportado na cidade em outro momento. Consta, inclusive, que suas relações foram mais estreitas com a colônia portuguesa do que propriamente com a espanhola, tendo deixado parte de sua fortuna à Santa Casa de Misericórdia, quando faleceu, em 1903. ${ }^{29}$

As décadas seguintes exibiriam uma outra condição aos emigrados. Ainda assim e, apesar das restrições, reveladoras das formas precárias de acomodação então encontradas no universo laboral da cidade, pudemos vislumbrar um outro segmento que nela se enquadrava de forma menos irregular, com emprego formal, documentado como operário, embora por si só, isso não fosse garantia de maior remuneração, a considerar as greves reivindicatórias que ocorriam com freqüência na cidade.

A propósito, as principais greves, conduzidas pela militância santista, tiveram como alvo as grandes companhias estabelecidas na cidade, como a Docas, a Inglesa, a City e a Light and Power. ${ }^{30}$

Coroando essa atmosfera, o movimento sindical vai se constituindo na cidade pela mão do imigrante estrangeiro, de quem, durante décadas, guardou indisfarçável sotaque. Poucas são as fontes conservadas desse período, porém é possível dele destacar algumas lideranças, dentre as quais a figura do espanhol Primitivo Raimundo Suarez - ou Florentino de Carvalho, alcunha que usava para despistar a polícia -, asturiano que chegara ainda criança a Santos e que, empregado na Cia. Docas, imprimiu orientação nova e liderança ao movimento sindicalista da cidade. "Os trabalhadores dos armazéns e carregadores do cais são cerca de 3.500 . $\mathrm{Na}$ sua maioria são portugueses e espanhóis; os brasileiros ocupam o terceiro lugar", informava o Boletim do Departamento Estadual do Trabalho, para o ano de $1912 .^{31}$ 


\section{Dôssie Imigração}

Com o salto de crescimento da cidade, no limiar do século XX, e as inúmeras possibilidades geradas pelos negócios com o café, assistimos a expansão de diversos setores comerciais e de serviços, à testa dos quais pudemos encontrar muitos espanhóis.

Diretamente envolvidos com o universo do café, uma das categorias que despontaram da necessidade de transportar o produto, antes que o porto moderno fosse inaugurado, foi a dos carroceiros, praticada de maneira informal, em um primeiro momento, mas incorporada, depois, ao rol de atividades oficialmente reconhecidas pelo poder público da cidade.

Com efeito, o café, antes de ter mecanizado o seu transporte da ferrovia ao porto, era transportado por carroças até o armazém, onde era classificado e ensacado. Aos funcionários do armazém cabia o ensacamento do produto, então sob a tutela das casas exportadoras. A esta operação, sucedia-se uma outra, também encabeçada pelos carroceiros, que era o seu transporte até os navios, onde eram acondicionados para o embarque.

Nos Livros da Câmara Municipal de Santos foram localizadas algumas licenças para carroceiros e carregadores espanhóis, como é o caso da licença concedida a Antonio Vazquez Fernandez, pela Câmara Municipal de Santos, em 1890. ${ }^{32}$ Anos depois, em 1906, esse orensano, em registro no CES, declarava-se operário, revelando a extrema mobilidade que tipificou esse período.

Também nos registros de funcionários na Folha de Pagamentos da Cia. Docas aparecem outras funções, onde também os espanhóis são encontrados. É o caso dos calceteiros, provavelmente trabalhando com as obras de construção do porto moderno, contratados para o assentamento de pedras ou paralelepípedos nas ruas, ou para a construção de muros de pedras, função em que se distinguiam os galegos, por tradição ancestral. Mas também é o caso dos estivadores, empregados diretamente envolvidos com o embarque do produto, que efetuavam o carregamento dos navios. ${ }^{33}$

As pequenas vendas de bairro proliferaram no período. Seriam representativas das atividades relacionadas ao comércio, afeita a muitos dos declarantes. Constituíam-se, na verdade e em maioria, de modestos armazéns onde era vendido de tudo. Geralmente instaladas em pequenos cômodos, guardavam um aspecto de pouco asseio e muitos eram conhecidos pelos nomes de seus donos. Alguns desses espanhóis pequenos vendeiros de bairro, donos de casas de pasto, restaurantes 
ou tabernas, ${ }^{34}$ além da autorização de praxe, necessitavam de licença extra da Câmara Municipal da cidade para o comércio de bebida alcoólica.

Um certo número desses insipientes comércios - cujos proprietários exibiam uma trajetória em geral marcada por dificuldades - evoluíam para restaurantes mais especializados, bares e outros estabelecimentos onde, eventualmente, praticava-se o comércio conjunto de diversos outros produtos.

Em geral iniciando com um pequeno comércio de secos e molhados, muitos alavançavam fortuna, ampliando o seu negócio: foi o caso da Família Vallejo. Felisindo Vallejo, orensano de Moreiras, teria chegado em 1893, conforme sua própria declaração no CES onde se registrou em 1904. Tinha, então, 25 anos de idade, era solteiro e se dizia do comércio. Odon Vallejo, seu futuro sócio e aparentado, somente apareceria nos registros do CES em 1910, quando declarou ter 20 anos de idade. Era da mesma localidade natal de Felisindo, dez anos mais jovem, e também se declarava do comércio. Consta terem iniciado com uma pequena portinha de secos e molhados, apenas no varejo. ${ }^{35}$

Ambos mantiveram-se nessa categoria até o ano de 1917, quando passaram a se declarar comerciantes, provavelmente pelo impulso que a empresa, então denominada Fernandez y Vallejo, já adquirira como importadora, passando a exibir freqüentes anúncios dos produtos que comercializava - azeite; azeitonas de Sevilla; conservas Trevijano; sardinhas da Galícia; vinhos de Jerez e Rioja; Sidra champagne; anis, etc. ${ }^{36}$

O crescimento da atividade comercial na cidade acompanhou de perto as mudanças nela introduzidas, intensificando-se e diversificando-se continuamente. Pela via do comércio, importante meio de ascensão social e prestígio, os imigrantes alcançavam visibilidade e reconhecimento, muitas vezes não apenas entre seus conterrâneos.

Dessa forma, e também pela via do comércio, outro Vallejo também construiria fortuna. Manuel Vallejo Perez, de Cresciente, Pontevedra, teria chegado ao Brasil em 1900, sozinho, e com apenas onze anos de idade. Consta que teria trabalhado inicialmente como ajudante de padaria, dormindo sobre sacos de farinha, para economizar. ${ }^{37}$

Certamente amealhara algumas economias, pois, já em 1912, com 24 anos de idade, declara-se do comércio, no registro então efetuado no CES. Em 1927, com outros sócios -Antonio Alonso Gonzalez, ${ }^{38}$ Ciriaco 


\section{Dôssie Imigração}

Gonzalez $^{39}$ e Irmãos Flores -, Manuel Vallejo teria construído o Cassino Monte Serrat. Responsável também pelo sistema de funiculares que davam acesso ao local, nesse cassino, de acesso restrito, reuniam-se autoridades que pretendiam permanecer no anonimato. O complexo todo, compreendendo também os salóes de festa, passou a ser administrado pessoalmente por Vallejo, a partir de 1946.

Francisco Bouzas é outro desses exemplos. Tendo chegado em 1897, conforme declaração no seu primeiro registro consular realizado dois anos depois, esse galego de Pontevedra, como muitos, declarou-se jornalero. Em 1908, porém, em outro registro realizado, a profissão declarada era a de operário e pouco depois, em 1913, já encontramos anúncios no EDE do seu estabelecimento, denominado Empório Comercial, armazém em que comercializava "bebidas finas e gêneros de primeira qualidade", estabelecido à rua General Câmara, 85, esquina com Senador Feijó. ${ }^{40}$

São inúmeros os exemplos de trajetórias que mediaram essa escala ascendente e o modo como se processou esse percurso assimétrico, largamente ensejado por artifícios e descontinuidades, de modo que não há como se estabelecer um modelo, mas apenas algumas tipologias sugestivas de possibilidades.

Assim, e também pela via do comércio deu-se a ascensão de Severino Torrecilla. Chegado à cidade em 1888, natural de Logroño, já casado e com 37 anos, Severino se declarou confitero no registro que fez no CES em 1901. Anos mais tarde, contudo, encontramos o reclame do seu estabelecimento: o Café e Confeitaria del pueblo no EDE. ${ }^{41}$

A família Flores apresentou, durante duas décadas, intensa participação na gestão do Centro Espanhol de Santos. Justino Flores Fernandez, eleito o primeiro vice-presidente da Junta Diretiva do Centro Espanhol, em 1895, ${ }^{42}$ declarava-se, não obstante, em seu primeiro registro no CES, realizado em 1911, como natural de Goyan, Pontevedra e do campo. Diferentemente dele, os demais membros da família Flores, dentre os quais Francisco Flores Fernandez, com data de chegada à cidade no ano de 1899, declarava-se, em 1906, do comércio e, onze anos depois, provavelmente já estabelecido, dizia-se comerciante, com negócio à rua General Câmara, 302, a mesma rua do estabelecimento de Bouzas.

Outro ramo da família Flores, porém com origem em León, teve enorme prestígio na cidade. Trata-se de Agustín e Felix Flores Nieto, proprietários de uma fábrica de produtos à base de banana denominada, não sem razão, 
A Leoneza, que funcionava na Rua da Constituição. Ambos costumavam realizar seus registros no CES em que se intitulavam comerciantes e a aparição freqüente nos anúncios no EDE são o melhor atestado da expansão dos seus negócios. Ali, nos primeiros anos da década de 1910, era comum encontrar reclames de La Leonesa, também como padaria e armazém de comestíveis, então localizada na Rua Brás Cubas, 77.43

Inúmeras estratégias, artifícios e práticas podem ser contabilizadas na constituição dessas casas comerciais, atestando situações, circunstâncias e condições diversas. Era comum, por exemplo, a formação de sociedades (\& Co. ou \& Cia.) com um conterrâneo ou aparentado, cuja necessidade se impunha como condição para ampliar o raio de ação, quer seja para o levantamento do capital necessário para a abertura ou ampliação do negócio, quer seja para a divisão das despesas ou das tarefas - as quais envolviam habilidades diferenciadas, como conhecimento do ramo, do produto e dos fornecedores e alguma prática relacionada ao trato dos valores envolvidos, perícia para cálculo de comissões e prestação de contas, enfim, aspectos contábeis correlatos.

Nessa esteira, foram muitas as sociedades que se constituíram no universo santista, pelos espanhóis. Temos por exemplo, a sociedade de Costillas \& Flores, que freqüentava regularmente as páginas publicitárias do EDE. Sua empresa tinha um sugestivo nome fantasia: Al Progreso Gran Depósito y Fábrica de Muebles a Electricidad, e apresentava-se com dois endereços: o depósito, na Rua do Rosário, 50 e as oficinas e o escritório na mesma rua, no $n^{\mathrm{o}} 144 .{ }^{44}$

Do mesmo modo, encontramos o Central Hall, de Conde \& Cia., sucessores de Nieto \& Conde, Bar e Restaurante que funcionava na Praça da República, 15, também operando com importação de vinhos e conservas; a Padaria e Confeitaria Democrata, de Gonçalves \& Prieto, na rua São Leopoldo, $5^{45}$; a Grande Padaria Nacional, de A. Gonzalez Fernandez \& Hermanos, na rua do Rosário, $338^{46}$ ou, ainda, a firma Pascual Gómez \& Cia. que atuava, nessa mesma década, como importadora de gêneros nacionais e estrangeiros, operando, igualmente como agente marítima e despachante de aduana, na Praça da República, $1-1^{\circ}$ piso. $^{47}$

O trabalho por comissionamento era outra das estratégias possíveis para alavancar um negócio. Nesse caso, o comerciante recebia uma porcentagem pela venda, sem ter de, necessariamente, arcar com o custo das mercadorias. Assim funcionava a Ortiz \& Cia., na rua Paula Souza, 65, em São Paulo e com filial em Santos: "compra e vende cereais, café e 


\section{Dôssie Imigração}

algodão, pagando os melhores preços da praça, cobrando comissões mínimas e prestando contas rápidas", dizia o anúncio, atestando a crescente concorrência no negócio. ${ }^{48}$

No Livro de Despesas e Receitas da Câmara Municipal de Santos, há alguns outros exemplos de licenças concedidas especialmente para o comércio de secos e molhados importados, bem como para o estabelecimento de casas comissárias. ${ }^{49}$ Eles, os comissários, trabalhando sob a forma de comissão e representação, "formavam o grupo mais próspero no meio comercial", afirma Deaecto, ${ }^{50}$ para completar depois: "E também no industrial e agrícola”.

Esses depositários, como também eram chamados aqueles a quem se confiava a representação de determinada empresa ou mercadoria, passam a aparecer nos anúncios publicitários do EDE a partir das primeiras edições examinadas, em 1912, através dos quais divulgavam um variado sortimento de produtos, desde gêneros alimentícios até máquinas.

$\mathrm{Na}$ verdade, era em Santos que se localizava a maioria de seus escritórios, também assíduos nas páginas do EDE, onde compareciam com grandes anúncios, proporcionais ao extenso inventário de produtos que representavam e/ou importavam.

Apenas para constar, uma das maiores, senão a maior delas, era a Troncoso \& Hermanos, que pertencia aos irmãos Secundino e Silvano, galegos de Pontevedra, cuja diversidade de funçôes era admirável: importadores; agentes marítimos; consignatários de empresas de navegação; casa de câmbio, além de serem representantes de diversas marcas de produtos alimentícios espanhóis. ${ }^{51}$

Silvano Troncoso, a propósito, desempenhava, nesse período, o cargo de vice-cônsul, ao mesmo tempo em que gerenciava o estabelecimento de Santos, enquanto seu irmão, Secundino, voltava a viver na Espanha. ${ }^{52}$

A exploração do ramo hoteleiro parece ter sido também um dos focos dos espanhóis estabelecidos na cidade de Santos. A crescente urbanização e o trânsito de pessoas pela cidade faziam desse um segmento extremamente próspero.

Havia, contudo, outros interesses envolvidos. O Hotel Madri, do galego de Coruña Faustino Vazquez, parece ter-se envolvido em confusão, por abrigar prostitutas em seu estabelecimento. Este se localizava no Largo da 
Banca (banca de peixe), junto ao vasto comércio ambulante e informal da cidade, que depois seria transferido para o mercado previamente construído para esse fim, na Praça Iguatemi Martins, em 1902.53

O Hotel Continental, com matriz na capital de São Paulo, pertencia a Agapito Alvarez talvez aparentado de Leandro Alvarez, proprietário do Hotel do Porto. Leandro era orensano e chegara em 1895, conforme sua declaração no CES onde esteve em 1904; tinha 22 anos, era solteiro e se dizia do comércio. Ambos publicavam com regularidade reclames no EDE, bem como os proprietários do Hotel 2 de maio, ${ }^{54}$ Bralt \& Tortosa. ${ }^{55}$

Defronte a aduana, à Praça da República, 56, funcionava o Gran Hotel España, de Luis Gómez Rodrigues. ${ }^{565}$ EDE, 01 de outubro de 1913. Este, em seu registro no CES de 1901, dizia-se cocinero, nascido em Pontevedra, 24 anos e solteiro.

\section{Notas (in)conclusivas}

Conforme ficou demonstrado, na Santos que exibia, no limiar do século $\mathrm{XX}$, um acelerado ritmo de crescimento, coexistiam inúmeros e ambíguos sinais que representavam, ao lado do seu aspecto progressista e dinâmico, o eloqüente atestado dos paradoxos que permeavam a vida da cidade em seu conflituoso cosmopolitismo.

Por meio desse artigo, procuramos sinalizar alguns dos indisfarçáveis conflitos enfrentados pela cidade, do mesmo modo que procuramos refletir sobre os modos alternativos empregados pelo espanhol nela estabelecido de, hábil e improvisadamente, penetrar nas frestas e se imiscuir nas brechas por ela abertas, driblando a marginalização a que se viam submetidos.

$\mathrm{Na}$ recuperação de algumas dessas formas de inserção, é inevitável reconhecer a existência de um segmento dinâmico, constituído por setores emergentes da colônia. Conseguindo galgar patamares variados na escala social e responsáveis, em última análise, pela criação dos núcleos e associações étnicas - que vinham ao amparo dos conterrâneos, nas questóes urgentes e inadiáveis que avultavam à proporção que cresciam os problemas da cidade em sua tumultuária transformação -, eles formavam, com a parcela majoritariamente subalterna dessa população imigrante, o perfil do espanhol, cuja singularidade buscamos recuperar, na reconstituição que vimos realizando. 
Notas e Referências

1 Marília Klaumann CÁNOVAS. Hambre de Tierra. Imigrantes espanhóis na cafeicultura paulista, 1880-1930. São Paulo: Lazuli, 2005.

2 Idem. Imigrantes espanhóis na Paulicéia. Trabalho e sociabilidade urbana, 18901922. São Paulo: Edusp/Fapesp, 2009.

3 Wilson Toledo MUNHÓS. Da circulação trágica ao mito da irradiação liberal: negros e imigrantes em Santos na década de 1880. São Paulo, PUC-SP: Dissertação de Mestrado, 1992, pp. 89 e ss.

4 SÂO PAULO. Recenseamento da Cidade e do Município de Santos em 31 de dezembro de 1913. Prefeitura Municipal de Santos. Santos, 1914, p. XVII.

5 Wilson Roberto GAMBETA. Soldados da saúde. A formação dos serviços de saúde pública em São Paulo. São Paulo, FFLCH-USP: Dissertação de Mestrado, 1988.

6 Betralda LOPEZ. O porto de Santos e a febre amarela. São Paulo: FFLCH-USP, 1974.

7 Guilherme ÁLVARO. "A campanha sanitária de Santos”. In: Serviço Sanitário do Estado de São Paulo. São Paulo: Casa Duprat, 1919. p. 55.

8 W. T. MUNHÓS. Op. Cit., p. 105.

9 MADRID. El Mundo, 28 de julho de 1911. Archivo Histórico del AMAE Archivo Ministerio Asuntos Exteriores. Ofícios da Legação Brasileira em Madrid.

10 Roberto SIMONSEN. Evolução Industrial do Brasil e outros estudos. São Paulo: Brasiliana/Nacional/Edusp, 1973, p. 25.

11 Pierre DENIS. O Brasil no século XX. Lisboa: Antiga Casa Bertrand, José Bastos \& Cia. Editora, s/d, p. 152.

12 Maria Alice Rosa RIBEIRO. História sem fim ... Inventário da saúde públicaSão Paulo, 1880-1930. São Paulo: Editora Unesp, 1993, p. 105.

13 Depoimento de Márcia Dieguez, residente em Santos, 17 de março de 2003 (fonte oral).

14 El Diário Español (EDE), 17 de fevereiro de 1922.

15 BRASIL. Recenseamento realizado em $1^{\circ}$ de setembro de 1920. Ministério da Agricultura, Indústria e Comércio. Directoria Geral de Estatística, Rio de Janeiro: Imprensa Oficial, 1962.

16 Marília K. CÁNOVAS “El Diario Español y las asociaciones españolas en São Paulo, en las primeras décadas del siglo XX”. In: Juan Andrés Blanco Rodríguez (ed.). El asociacionismo en la emigración española a América. Salamanca: Junta de Castilla y Leon/Uned Zamora, 2008, pp. 389-422.

17 Avelina Martinez GALLEGO. "Espanhóis". Cadernos de migração. São Paulo: 5. CEM- Centro Estudos Migratórios, 1995, p. 40.

18 EDE, 31 de julho de 1913. Outros participantes da reunião: Parada, Eduardo; Bojart, Juan; Lobariñas Fernandez, Segundo e Pérez Rodriguez, Evasio. Cf Eliane Veiga PORTA. Imigrantes espanhóis em Santos, 1880-1920. São Paulo, FFLCH-USP: Mestrado, 2008, p. 82. 

seu "mundo submerso", título de uma coletânea de sua autoria, revelam um universo de dimensões e percepções da cidade amplas de significados, na recuperação de aspectos que, de outro modo, seriam irrecuperáveis. Há outros autores importantes, nessa trilha: Ranulpho Prata, em Navios Iluminados apresenta um expressivo painel da sociedade santista das primeiras décadas dos Novecentos, numa descrição que transita pelo concorrido mundo do trabalho, com apelo a aspectos psicológicos de seus protagonistas, fixando-se numa crítica de costumes. Cf. Nelson Salazar MARQUES,. Imagens de um mundo submerso. (Minhas memórias da cidade de Santos). Santos: vol. I, Ed. Leopoldianum, 1995; São Paulo, vol. II, Ed. do Escritor, 2000; São Paulo: vol. III, Ed. do Escritor, 2001 e Ranulpho PRATA. Navios iluminados. São Paulo: Scritta, 1996.

BRASIL. Arquivo Nacional (doravante A .N.) - Série Indústria e Comércio: Registro de matrícula de estabelecimentos comerciais pertencentes a eles naquela cidade, Livro $\mathrm{IC}^{3} 57$.

135-146; Dulce Pompeo de Camargo LEMME. Hoje há ensaio: a greve da Companhia Paulista de 1906. Campinas: Papirus, 1985. operário e cultura urbana. São Paulo: Editora da Universidade Estadual Paulista, 1992, p. 115.

32 Eliane Veiga PORTA. Op. Cit., p. 137.

33 Idem, p. 52.

34 Eram os seguintes: Covas Perez, Manuel; Martins Ruas, Antonio; Caballeros, José; Vasquez Estevan, Damas; Rua, Feliciano; Perez, Romão; Castelloes, Antonio José; Garcia, Ignácio Antonio; Lopes, Manuel Antonio; Caetano Gil, Amélio; Caetano Gonzalez, Amales; Lopez y Andrade, Antonio; Lopez Gil, Manoel; Fernandez, Sebastião; Manuel Perez e Irmão; Borges \& Cia.; R. Blanco, José; 
Rodrigues Peres, Manuel; Cajañas, Angel; Nunes \& irmãos; Garcia Lascale; Fernandez e Vasquez; Antonio Flores \& Cia; Nunes, Augusto; Souza e Rodrigues. In: PORTA, E. Op. Cit., pp. 52-3.

35 Eliane Veiga PORTA. Op. Cit., p. 53.

36 EDE, 27 de junho de 1913.

37 Eliane Veiga PORTA. Op. Cit., p. 149.

38 Declarando haver chegado ao Brasil em 1896, quando tinha 18 anos, Alonso Gonzalez era nascido nas Canárias e em seu registro no CES de 1906 se declarou "operário".

39 Ciriaco Gonzalez, nascido em Pontevedra, chegara em 1897, com 22 anos de idade, e em seu registro de 1906 no CES se declarava "albanil" (pedreiro).

40 EDE, 04 de janeiro e 01 de fevereiro de 1913.

41 EDE, 26 de junho de 1913.

42 Eliane Veiga PORTA. Op. Cit., p. 140.

43 EDE, 30 de julho de 1913.

44 EDE, 04 de agosto de 1913.

45 EDE, 14 de abril de 1913.

46 EDE, 28 de abril de 1913.

47 EDE, 31 de julho de 1913.

48 EDE, 12 de março de 1922.

49 Foram os seguintes localizados: Esteves \& Cia.; González, Francisco; Garcia, Ignácio Antonio; Garcia, Irmão \& Cia.; Perez \& Mattos; Castelloes, Antonio José; Corvello, Raimundo; Rodriguez, Leonel José. In: Eliane Veiga Porta. Op. Cit., pp.53-54.

50 Marisa Midori DEACTO.Comércio e vida urbana na cidade de São Paulo (18891930). São Paulo: Editora Senac, 2002, p. 124.

51 EDE's, 08 de janeiro de 1912, 27 de junho de 1913 e outros mais.

52 EDE, 18 de outubro de 1913.

53 Eliane Veiga PORTA. Op. Cit., pp. 33 e 143.

54 A data de 2 de maio era comemorativa para os espanhóis; a Dois de Maio de 1866 a Espanha, em sua empresa imperialista fincou, pela primeira vez, sua bandeira no Pacífico.

55 EDE, 27 de junho de 1913.

56 EDE, 01 de outubro de 1913. 